10.4274/tjps.65624

Research Article

\title{
Green preparation of citric acid cross-linked starch for improvement of physico-chemical properties of Cyperus starch
}

\author{
$\underline{\text { Bunmi Olayemi }}^{1}, \underline{\text { Christianah Yetunde Isimi }}^{1}, \underline{\text { Kokonne Ekere }}^{1}, \underline{\text { Ajeh Johnson Isaac }}{ }^{1}, \underline{\text { Judith }}$
} Eloyi Okoh $^{1}$, Martins Emeje ${ }^{2}$

${ }^{1}$ Department of Pharmaceutical Technology and Raw Materials Development, National Institute for Pharmaceutical Research and Development (NIPRD), Idu Industrial Area, Abuja, Nigeria. ${ }^{2}$ Centre for Nanomedicine and Biophysical Drug Delivery, National Institute for Pharmaceutical Research and Development (NIPRD), Idu Industrial Area, Abuja, Nigeria.

INTRODUCTION: This study was undertaken to assess the properties of Cyperus esculentus tuber starch cross-linked with citric acid from liquid substrates of orange peel derived via the natural solid-state fermentation process; a green-approach.

METHODS: The flow properties of the prepared starches were evaluated using standard methods. Water holding capacity, swelling capacity, moisture sorption capacity, gelatinization temperature using Differential Scanning Calorimetry (DSC), morphology, Fourier Infrared Spectroscopy and $\mathrm{pH}$ of the starches were evaluated.

RESULTS: According to the results the $\mathrm{pH}$ of the cross-linked starches were lower (3.39 - 4.07) than that of the native starch (5.25) and flow profile was found to improve. Water holding capacity $(90.67-96.69 \%)$ of the cross-linked starches were higher while emulsion capacity (15.33) was similar to that of the native starch (15.33). No change was observed in the morphology of the granules of the cross-linked starches. The infrared spectra of the native and cross-linked starches showed identical peaks; the enthalpy of gelatinization ( $\Delta \mathrm{Hgel})$ of the crosslinked products were found to differ from that of the native starch. The modified starches show propensity of being exploited as binding agents in food and pharmaceutical industries.

DISCUSSION AND CONCLUSION: The green process of modification has proved to be value addition to the processes of starch modification available.

Keywords: : Cyperus esculentus tuber starch, cross-linking, citric acid, orange peel, cross-linked starch

Bunmi Olayem, ${ }^{1}$ Department of Pharmaceutical Technology and Raw Materials Development, National Institute for Pharmaceutical Research and Development (NIPRD), Idu Industrial Area, Abuja, Nigeria.

0000-0001-5759-7176

olubunmibiala@yahoo.co.uk

$+2348033532299$

13.09.2019

05.12.2019 


\section{INTRODUCTION}

In recent past, starch has been widely sourced from plant roots, seeds, leaves and fruits but modern trends in technologies and processes have moved on to adopt other sources to obtain starch. The non-conventional sources have been exploited for development of starch with wide applicability in pharmaceutical formulations as tablet binders and disintegrants, glidants, suspending and emulsifying agents. ${ }^{1-6}$

Although starch in its native form has many potentials, its poor flow properties, instability when exposed to high temperature and under high shear rate, variations in $\mathrm{pH}$, high retrogradation, its limited solubility in common organic solvents and freeze-thaw processes make them less desirable for industrial applications. ${ }^{7-9}$ The goal of many formulation scientists therefore, is to find means of overcoming these limitations while developing versatile starch-based excipients that have multifunctional applications. One of the solution to this demanding technological need is to modify the properties of native starch. This involves tweaking its physical and chemical characteristics to improve its functionality with useful structural attributes via physical, chemical, enzymatic and genetic means. ${ }^{10-13}$

Chemical modification was the most prevalent means of starch modification employed in the last century and the developed products have found several applications in the food, textile and pharmaceutical industries. ${ }^{14}$ This type of adaptation involves the incorporation of functional groups via chemical reactions that can alter the starch molecule or substitute some functional groups. However, factors like starch source, ty pe of reactant, concentration and time of reaction and $\mathrm{pH}$ of the reacting medium influences the outcome of the modification. Chemical modification yields starch products through etherification, esterification, decomposition, grafting and cross-linking techniques. ${ }^{12}$

Crosslinking introduces a covalent interconnection via hydrogen bonds in starch granules which provides strong bonds between the molecules and restrict the movement of the polymer chains. ${ }^{15-}$ ${ }^{16}$ This decreases the rate of starch retrogradation which consequently increases rigidity and hardness of its gel; in addition to enhancing its solubility in organic solvents. ${ }^{8,17}$ Various reagents are used in the crosslinking reaction and these determine the property of the cross-linked product. A study by Hirsch and Kokini ${ }^{18}$ showed that the reaction of waxy maize starch with phosphorous oxychloride produced starch with high viscosity and minimum swelling. In their study, Wattanachanta et al. ${ }^{19}$ showed that crosslinking sago starch with a mixture of sodium trimetaphosphate (STMP) and sodium tripolyphosphate (STPP) produced starch with high resistance to acids, rid gels and high freeze-thaw stability. Another study investigated the reaction of chlorinated corn starch with formaldehyde and observed that increasing the quantity of formaldehyde while reducing the extent of oxidation improved the efficiency of the reaction process and the products. ${ }^{20}$

In a completely different study, Chowdary and Chaithanya ${ }^{21}$ cross-linked potato starch gelatinized in the presence of urea and found that the process of crosslinking imparted better flow on the starch although the product was insoluble in aqueous, alkaline and acidic media. However, they observed that tablet formulations produced with the cross-linked starch prolonged drug release for up to $24 \mathrm{~h}$ and thus concluded that the cross-linked product could be used in the preparation of extended release tablet formulations.

Omojola et al. ${ }^{7}$ investigated the effect of crosslinking on Icacina trichantha tuber starch and observed that the modified starch had higher water absorption capacity over the native starch 
with no gelatinization occurring upon heating. They proposed that the modified starch could be a more effective tablet disintegrant than the native Icacina trichantha tuber starch. In a different study, Omojola et al. ${ }^{22}$ also explored reaction of Cola nitida starch with acetic anhydride and sodium tripolyphosphate and their result showed that the cross-linked starch obtained had lower viscosity, solubility and swelling than the unreacted starch and was thus, suggested for use as a food thickener.

The study by Isah et al. ${ }^{9}$ reported that Digitaria exilis starch cross-linked with citric acid decreased the oil and water absorption capacities, foam capacity and $\mathrm{pH}$ of the modified starch. They observed from the scanning electron microscopy (SEM) that crosslinking did not alter the shape and morphology of the starch granule while FTIR showed the presence of an additional peak. Their results suggested the use of the cross-linked Digitaria exilis starch in the food and pharmaceutical industry.

Agents like citric acid have been commonly used in the process of crosslinking. Citric acid (CA), is a very essential organic acid that is widely utilized in the food and pharmaceutical industries.

It is an intermediate of the tricarboxylic acid cycle, and is found in a variety of acidic fruit juices, particularly the citrus family. ${ }^{23}$

Citrus fruits are readily available in most regions of the world and annually, the citrus processing industries generate tons of residues, including peels and segment membranes, after extraction of the citrus juice for commercial purposes. However, these wastes are usually not put to use/reasonable use thus they constitute environmental hazard. For example, the solid wastes increase the burden already present at the landfills where they are deposited while liquid wastes disposed into the rivers could cause nutrient imbalance, loss of oxygen and consequently death of the aquatic life. Failure to exploit the potential of these wastes could also impact negatively on the economy. With an estimated annual production of about 10,000,000 tons, citric acid is one of the fermentation products with the highest level of production worldwide. ${ }^{24}$

In recent years, researchers and scientists have explored various manufacturing processes and products with marginal likelihood of causing harm while also improving the sustainability of product development. ${ }^{25-26}$ This can be achievable through the green approach system; which entails manufacturing processes that create technologies which are safer for the environment and those working in those environment in addition to reducing wastes. Innovations via green synthesis has led to development of diverse products for different applications including the production of citric acid via fermentation of the citrus by-products using micro-organisms. ${ }^{27-28}$ Different techniques have being employed in the production of citric acid via fermentation and they include; the submerged, surface and solid state fermentation with the latter being the simplest of all the techniques. ${ }^{29-30}$

Our intention is to use the green approach to obtain citric acid from fruit wastes which would serve as a precursor for the development of a pharmaceutical excipient. Therefore, the aim of this study is cross-link starch obtained from Cyperus esculentus seed using liquid substrates of orange peel derived via the natural solid-state fermentation process and evaluate its physiochemical properties.

\section{MATERIALS AND METHODS}

Materials 
Tigernut starch from the tuber of Cyperus esculentus (extracted in the Department of Pharmaceutical Technology and Raw Material Development, NIPRD, Abuja, Nigeria), Oranges (obtained from Karmo market, Abuja, Nigeria).

\section{Preparation of orange peel substrate}

Fresh oranges were procured from Karmo market, Abuja. The oranges were washed with water and the skin was separated from the pulpy segments of the fruit. Nine hundred (900) grams of the orange peel was soaked in $2.5 \mathrm{~L}$ of water and the $\mathrm{pH}$ of the mixture recorded. The $\mathrm{pH}$ of the soaked peels was then subsequently recorded on days 1,5 and 15 .

Preparation of starch

Tigernut starch was extracted using the method of Kunle et al. ${ }^{31}$.

Preparation of modified starch

The procedure described earlier ${ }^{32}$ was adopted with some modifications. The $\mathrm{pH}$ of the orange peel substrate was determined on the day 5 and $50 \mathrm{~mL}$ of the filtered substrate was poured in a beaker. This was then added in aliquots into $50 \mathrm{~g}$ Tigernut starch (TNS) placed in another beaker and mixed until a smooth paste was obtained. The resulting paste was spread on a tray and left to dry at room temperature for about $18 \mathrm{~h}$. The air dried product was then placed into the oven and dried at $60^{\circ} \mathrm{C}$ for $1 \mathrm{~h} 30 \mathrm{~min}$. the oven-dried product was size-reduced in a mortar using a pestle after which it was further dried in the oven at $130^{\circ} \mathrm{C}$ for $2 \mathrm{~h}$. The product (TS1) was then allowed to cool, weighed and stored in the desiccator for further analysis.

Other products of the modified starch (TS2 and TS3) were prepared according to the procedure stated above using orange peel substrate obtained on days 10 and 15 respectively.

\section{Evaluation of physicochemical properties of modified starch}

Morphology

A small quantity of TS was mounted on the microscope slide and examined under a light microscope (Leica DM light microscope) at a magnification $\mathrm{x} 400$. The shape of the starch product was extrapolated from the photomicrograph.

pH determination

The $\mathrm{pH}$ of a $10 \% \mathrm{w} / \mathrm{v}$ slurry of the starch product was determined at room temperature $\left(28^{\circ} \mathrm{C}\right)$ using the $\mathrm{pH}$ meter. Triplicate determinations were made and the mean was computed.

Angle of repose

The funnel method was used; $20 \mathrm{~g}$ each of the dried products (TS0, TS1, TS2 and TS3) was allowed to flow through a funnel clamped at a fixed height from a flat surface. The height (h) and radius (r) of the powder heap were measured and the angle of repose (A) was calculated as; $A=\tan -1 h /$

Bulk and tapped densities

The volume occupied by $20 \mathrm{~g}$ of the starch product in a graduated measuring cylinder was noted and the bulk density $(\mathrm{g} / \mathrm{mL})$ was calculated as a ratio of the powder weight to the volume occupied in the cylinder. Similarly the tapped density $(\mathrm{g} / \mathrm{mL})$ was computed as the ratio of powder weight to the volume it occupied after tapping the measuring cylinder 100 times.

Carr's compressibility index (CI) and Hausner ratio (HR)

The Carr's index (\%) was calculated using the formula below; tapped density - bulk density/tapped density $X 100$

Hausner ratio was computed as the ratio between the tapped and bulk densities. Swelling capacity 
A slurry of the starch product $(1 \% \mathrm{w} / \mathrm{v})$ was made in distilled water, the dispersion was heated on a water bath (Karl kolb, Dreiech West Germany) at $30{ }^{\circ} \mathrm{C}$ for $30 \mathrm{~min}$ with intermittent stirring. This was then centrifuged at $1500 \mathrm{rpm}$ for $30 \mathrm{~min}$, the supernatant was discarded, the weight of starch paste was determined and the swelling capacity was calculated as; $S(\%)=$ weight of wet starch/initial weight of dry starch $X 100$

This procedure was carried out for each of the starch products (TS0, TS1, TS2 and TS3) at 30 $40,50,60,7080$ and $90{ }^{\circ} \mathrm{C}$.

\section{Gelatinization temperature}

This was determined using differential scanning calorimetry (DSC). The starch samples (5 mg) were placed in the aluminum pan and a drop of water added. The samples were scanned between the 60 and $300{ }^{\circ} \mathrm{C}$ at a heating rate of $10^{\circ} \mathrm{C} / \mathrm{min}$ under constant nitrogen flow.

\section{Water holding capacity}

The method of Kornblum and Stoopak ${ }^{33}$ was adopted. The cross-linked starch dispersion (1 $\% \mathrm{w} / \mathrm{v}$ ) was placed in pre-weighed, stoppered centrifuge tube and shaken intermittently for 10 min after which it was left to stand for another $10 \mathrm{~min}$. The dispersion was then centrifuged at $1500 \mathrm{rpm}$ for $5 \mathrm{~min}$, the supernatant was discarded and the weight of the hydrated starch was determined. Hydration capacity was calculated using the equation below;

$$
H(\%)=\text { weight of dry starch } / \text { weight of starch sediment } X 100
$$

\section{Foam capacity}

The method by Isah et al. ${ }^{9}$ was adopted; $2 \% \mathrm{w} / \mathrm{V}$ dispersion of the starch product in water was homogenized for $5 \mathrm{~min}$. The homogenate was poured into a measuring cylinder $(50 \mathrm{~mL})$ and the volume recorded after $30 \mathrm{~s}$. The foam capacity was expressed as the percentage increase in volume.

\section{Emulsion capacity}

This was also carried out according to the method of Isah et al. ${ }^{9}$. The starch product was dispersed in water $(2 \% \mathrm{w} / \mathrm{v})$ and homogenized for $2 \mathrm{~min}$. After which vegetable oil $(2.5 \mathrm{~mL})$ was gradually added to the mixture and stirred continuously for $30 \mathrm{sec}$. The suspension was centrifuged at $1600 \mathrm{rpm}$ for 5 min and the volume of oil floating was determined. Emulsion capacity was computed as the quantity of oil emulsified per gram of the sample.

\section{Moisture content}

This was determined using the oven-dry method; the starch product $(0.5 \mathrm{~g})$ was placed into a dry crucible $\left(\mathrm{W}_{1}\right)$ and the crucible was placed in an oven at $100-105{ }^{\circ} \mathrm{C}$ for $10-12 \mathrm{~h}$ until constant weight was obtained. The crucible was then allowed to cool in a desiccator for $30 \mathrm{~min}$ and reweighed $\left(\mathrm{W}_{2}\right)$. Moisture content $(\%)$ was calculated as;

$W 1-W 2$

$$
\text { W1 } 10100
$$

\section{Moisture sorption capacity}

The starch product ( $1 \mathrm{~g})$ was placed in a tarred porcelain dish and weighed (W1), the dish was then placed in a desiccator containing distilled water. The sample and dish were weighed daily (W2) for 5 days and the moisture sorption capacity was determined as;

$$
W 1-W 2 / W 1 \times 100
$$

\section{Fourier Transform Infra-Red (FT-IR) spectral studies}

Native Tigernut starch and the cross-linked products (TS1, TS2 and TS3) were triturated with potassium bromide, made into pellets $\left(1 \mathrm{ton} / \mathrm{cm}^{2}\right)$ and the infra-red (IR) spectra taken between 
the scanning ranges 4000 and $400 \mathrm{~cm}^{-1}$ using the Nicolet iS10, Thermo Scientific (USA), FTIR spectrometer.

\section{RESULTS AND DISCUSSION}

Organoleptic properties of Tigernut starch and its cross-linked derivatives

The organoleptic properties of Tigernut starch and its cross-linked products are shown in Table 1. Native Tigernut starch (TS0) was white, tasteless, odorless smooth powder while the crosslinked products; TS1, TS2 and TS3 which had been reacted with orange peel substrates from days 5,10 and 15 respectively were observed to be off-white in color, odorless with characteristic taste and coarse to touch. The color change observed with the cross-linked products could be attributed to the color of the orange peel substrate used.

\section{pH of orange peel substrate}

The $\mathrm{pH}$ of the orange peel substrate on days $0,5,10$ and 15 is presented in Table 2 . The results show that the $\mathrm{pH}$ of the substrate was not consistent during the period of the study. The $\mathrm{pH}$ decreased to 2.00 by day 5 and increased to 2.79 by day 10 but decreased again to 2.30 by day 15. This could be as a result of fermentation; where microorganisms use carbohydrates from the substrate as a source of energy thus influencing the chemical environment of the substrate/medium. This process causes the growth of lactobacillus which produce organic acids that lower the $\mathrm{pH}$ of the medium. The absence of a trend in the $\mathrm{pH}$ of the substrate could be associated with the fact that at the beginning of the fermentation process, microorganisms consumed the nutrients from the orange peels and released organic acids into the medium thus lowering the $\mathrm{pH}$ but shortage of these nutrients after period of time could have resulted in consumption of the organic acids which led to an increase in the $\mathrm{pH}$ of the medium. Since the initial decrease in $\mathrm{pH}$ is attributed to production of citric acid, it implies that the effect of crosslinking on starch product treated with substrate from day 5 (TS1) would be greater than that from day 10 (TS2) when the $\mathrm{pH}$ was observed to increase again. The nature of substrates in the fermentation medium and method of by which the organic acids are produced are factors that influence the $\mathrm{pH}$ kinetics of the medium. ${ }^{34}$

Flow properties of Tigernut starch and its cross-linked derivatives Table 3 shows the result of the flow properties of Tigernut starch products (TS0, TS1, TS2 and TS3). Angle of repose of a material is a reflection of its flow ability; values $<30^{\circ}$ are an indication of excellent flow while those between 31 and 35, 36 and 40 and those $>40^{\circ}$ are indicative of good, fair and poor flow respectively. ${ }^{35}$ Values obtained for TS0 and TS1 were observed to be similar 33.06 and $34.66^{\circ}$ respectively showing that they possess good flow while those for TS2 and TS3 were lower (26.96 and $30.39^{\circ}$ respectively) and revealing that they have good to excellent flow ability.

The increase in CA probably resulted in better modification as a result of substitution of more OH groups on starch leading to less amorphous and better flowing product. Carr's compressibility index (CI) is a parameter that assesses the ability of a material to deform under pressure while Hausner ratio (HR) measures the cohesiveness of a powdered material by determining the degree of densification of that material. ${ }^{35}$ When CI of a material is $\leq 10$, between 16 and $20 \%$ or between 21 and $25 \%$, it signifies that the material has excellent, moderate or fair flow respectively. Consequently, HR of $\leq 1.11$ shows that the material is cohesive and become less cohesive when values are between 1.12 and 1.2. 
The results presented in Table 3 show that increasing the fermentation period improved the flow of the cross-linked starch products (TS1, TS2 and TS3) with TS3 having lower CI (25.24\%) and HR (1.34) than TS2 and TS1 which were found to have CI; $29.24 \%$, HR; 1.42 and CI; $30.36 \%$, HR; 1.45 respectively. These values were also observed to be lower than those obtained for the native starch $(32.13 \%$ and 1.47$)$ indicating that treatment of the starch with the orange peel substrate improved the flow of TS.

This result indicates that the cross-linked starch (TS3) would produce good compacts when pressure is applied during tablet compression. It also shows that there would be reproducible product manufacture and performance with consequent uniform drug distribution in the tablet batch.

\section{Physicochemical properties of Tigernut starch and its cross-linked derivatives}

The $\mathrm{pH}$ of native Tigernut starch; TS0 (5.25) was similar to that reported (5.60) by Kenneth et al. $^{36}$ in their characterization of Tigernut starch. The values obtained for the cross-linked products (TS1, TS2 and TS3) were found to be lower (4.07, 3.39 and 3.87 respectively) and could be linked to the varying $\mathrm{pH}$ of orange peel substrate used. This may also be attributed to the presence of carboxylic acid on the starch molecule leading to increasing acidity.

These values however, were within the range (3-9) specified for most starches used in the pharmaceutical, cosmetics and food industries. ${ }^{37}$ This result is also similar to some earlier reports ${ }^{7,34}$ where the $\mathrm{pH}$ of icacina trichantha tuber starch and tacca involucrate tuber starch cross-linked with citric were found to be 4.59 and 4.68 respectively. In addition, pastes from various modified starches have been documented to be acidic, the results of this study is therefore consistent with earlier reports. ${ }^{38-40}$

The water holding capacity of Tigernut starch products is presented in Table 4 . The water holding capacity of the cross-linked products (TS1, TS2, and TS3) were observed to increase with length of stay of the orange peel substrate. They were was also found to be appreciably (91.37, 90.37 and $96.69 \%$ respectively) than that of the native starch; TS0 (85.55\%). Water holding capacity shows the capacity of a material to retain water when pressure is applied or when heated; it is also the measure of the hydration capacity of that material. ${ }^{41}$ The observed increase in water holding cap acity may be ascribed the attachment of carboxyl groups on the starch molecules thus improving its ability to imbibe water. This phenomenon is desirable specifically in the application of such starch products as disintegrants in solid dosage formulations or as drug carriers for controlled drug delivery systems. ${ }^{39}$ This result is in tandem with those of icacina and tacca starch citrate. ${ }^{7,32}$ The study by Jyothi et al. ${ }^{42}$ also reported higher water holding ability of cassava starch citrate over the native cassava starch.

Foam and emulsion capacities are vital functional properties that determine the behavior and applicability of these starches in processing, consumption and storage. The foam capacity of the cross-linked products (TS1, TS2, and TS3) were observed to be the same (3.33) and slightly higher than that of the native starch (3.07). Their emulsion capacities on the other hand was found to be the same $(15.33 \%)$ as that of the native starch indicating that their emulsifying property was not affected by modification of the starch. These results demonstrate the ability of the modified starches (TS1, TS2 and TS3) to decrease surface tension and as such may be employed as emulsifiers in food, cosmetic and pharmaceutical products.

Moisture content of the cross-linked starches increased with increase in concentration of the cross-linking substrate $(7.8,8.1$ and $9.2 \%$ respectively) and were generally comparable with that of the native starch $(8 \%)$. These values are within the limit specified for pharmaceutical 
starches ${ }^{43}$ as presence of excessive moisture can impact negatively on the flow and mechanical properties of the material. ${ }^{44}$ In addition, it can promote growth of micro-organisms in the formulation during packaging and storage as well as decrease the stability and shelf-life of the formulation. ${ }^{45}$

Moisture sorption capacity is a measure of moisture sensitivity and an indication of the physical stability of a material under storage. ${ }^{46}$ The cross-linked starches showed similar sorption capabilities (5.42, 5.84 and $5.54 \%$ respectively) with the native starch (5.87\%). Materials with low values have less tendency to undergo hydrolytic degradation and as such, are beneficial in formulations containing moisture sensitive drug components.

Swelling capacity of TS0, TS1, TS2, and TS3 over a range of temperatures $\left(30-90^{\circ} \mathrm{C}\right)$ is displayed in Table 5. Swelling characteristics portrays the ability of starch granules to absorb water when exposed to heat. Swelling over different temperature ranges is important as evaluates the behavior of starches under industrial conditions. The results show a general increase in starch volume as the exposure temperature increased for the native and cross-linked starches although swelling was found to be higher at higher temperatures $\left(60-90^{\circ} \mathrm{C}\right)$ than at lower temperatures $\left(30-50{ }^{\circ} \mathrm{C}\right)$. This pattern has been ascribed to intrinsic binding forces that tend to weaken at the varying temperatures ${ }^{47}$ and has also been reported by Omojola et al. ${ }^{48}$ However, an exception to this trend was observed with TS2 where swelling was observed to appreciably increase at $80^{\circ} \mathrm{C}$ but decreased at $90{ }^{\circ} \mathrm{C}$. TS1, TS2 and TS3 showed similar swelling pattern at $30,40,50$ and $60^{\circ} \mathrm{C}$. However, at $70^{\circ} \mathrm{C}$, TS2 was observed to have less swelling than TS1 and TS3 and at $90{ }^{\circ} \mathrm{C}$ no further swelling was observed in TS2 and TS3. The swelling profile of TS1 was observed to be the most consistent (progressively increasing) of all the starches.

Nonetheless, the swelling profile of the native and cross-linked starches were similar. This suggests that cross-linking did not have any effect on granule swelling and could be attributed to increased resistance to starch granule swelling due to higher bond strength conferred by crosslinking; this has also been reported by Xie and Liu. ${ }^{49}$

Limited water uptake into starch granules imply that structural break down of the granules will not take place as such, these starches may not be good candidate disintegrants for solid dosage formulations. Our result is however different from those of Adebiyi et al. ${ }^{32}$ where Tacca starch citrate was observed to have higher swelling power than that of the native Tacca starch. This can be attributed to differences in the biological sources of the starch material and the methods of starch extraction employed.

Morphology of the native and cross-linked starches are shown in Figure 1. The native starch (TS0) have small and large-sized, oval-shaped, smooth granules occurring mostly in single unaggregated forms (TS0). The cross-linked starches (TS1, TS2 and TS3) are more uniform in size, oval-shaped and occur in aggregates which was observed to increase with the time of crosslinking (TS1>TS2>TS3). Application of the orange peel substrate to modify Tigernut starch here did not rupture or change the granule morphology, showing that the modified starch would pack more closely and consolidate better than the native starch under applied pressure resulting in higher bond strength. Starch granules with small and uniform sizes are widely used in pharmaceutical and food industries ${ }^{50}$ as such this cheap substrate cross-linked starches could find application in these industries.

Fourier transform infra-red (FT-IR) of Tigernut starch and its cross-linked derivatives 
Fourier transform infra-Red (FT-IR) spectra of the starch products are presented in Figure 2. The native starch shows significant peaks at $3240 \mathrm{~cm}^{-1}$ while those of the TS1, TS2 and TS3 are $3257.7,3235.3$ and $3250.2 \mathrm{~cm}^{-1}$ respectively all indicating $\mathrm{OH}$ stretching. The band $2929.7 \mathrm{~cm}^{-1}$ of the native starch is characteristic of $\mathrm{C}-\mathrm{H}$ stretches associated with ring hydrogen atoms and was observed to slightly decrease to $2926 \mathrm{~cm}^{-1}$ in all the cross-linked products. The change in intensity in the $\mathrm{C}-\mathrm{H}$ stretch could be due to possible change in amylose and amylopectin content of starch and this is known to be responsible for variation in the physicochemical properties starch. All the starches showed peaks at about 1640, 1338 and $1140 \mathrm{~cm}^{-1}$ indicating the presence of intra-molecular hydrogen bonds, $\mathrm{C}-\mathrm{H}$ bending and $\mathrm{C}-\mathrm{O}$ stretching. Bands at $708-928 \mathrm{~cm}^{-1}$ portray the characteristic identity of the starch. ${ }^{50}$

Differential scanning calorimetry (DSC) of Tigernut starch and its cross-linked derivatives The behavior of the starch granules of all the samples (TS0, TS1, TS2 and TS3) when subjected to heat is shown in the DSC thermograms presented in Fig. 3a, b, c. Starch gelatinization refers to series of processes that occur when starch is heated and converted to paste; the temperature at which gelatinization occurs is dependent on the crystalline nature of the starch molecules. This transitional phase of starch granules is an important characteristic that makes them applicable in industrial processes.

The thermal properties of the native and modified starches are presented in Table 6 . The onset temperature of gelatinization $\left(\mathrm{T}_{0}\right)$ of native starch $(\mathrm{TS} 0)$ is observed to be lower $\left(60.35^{\circ} \mathrm{C}\right)$ than those of the modified starches (104.16 and $113.18^{\circ} \mathrm{C}$ for TS2 and TS3 respectively). This is attributable to increased granule strength conferred as a result of crosslinking, thus higher temperature is required to initiate starch gelatinization. Increase in gelatinization temperature also indicates better binding ability of the starch showing that the cross-linked starches possess better binding capability than the native starch. Some studies have also reported increase in gelatinization temperature with other cross-linked starches which is related to decreased mobility of amorphous chains in the starch granule. ${ }^{16,38}$ Similarly, the peak $\left(T_{p}\right)$ temperature and conclusion temperature $\left(\mathrm{T}_{\mathrm{c}}\right)$ of the modified starches were also observed to be generally higher than those of TS0 (125.59 and $134.44^{\circ} \mathrm{C}$ respectively). This suggests that the modified starches have acquired more crystaliine forms than the native starch; this is in tandem with literature where positive correlation between onset and peak temperature of gelatinization and the amorphous/crystalline nature of materials have been reported. ${ }^{50-51}$

The enthalpy of gelatinization $(\Delta \mathrm{H})$ is directly related to the crystalline nature of starch granules (amylopectin) and demonstrates the extent to which the bond order within the starch molecule is broken and melted during the heating process. The differences in $\Delta \mathrm{H}$ is considered to be the result of dissimilar bond forces within the starch granules. ${ }^{52}$ Higher enthalpies of gelatinization as observed with TS0 and TS1 [1926.95 and $2120.73 \mathrm{~J} /\left(\mathrm{g}^{*} \mathrm{~K}\right)$ respectively] shows that higher energy is required to disentangle these bonds than those of TS2 and TS3, thus showing the effect of cross-linking on bond rearrangement within the starch granules. Therefore, cross-linked starch, TS1 would function as a better binder than TS2 and TS3.

Generally, higher $T_{o}, T_{p}, T_{c}$ of the modified starches suggest high degree of crystalline association within those granules than in TS0; these resulted in higher structural stability and resistance to gelatinization as have been previously reported.$^{53}$ Low temperatures observed in TS 0 could be an indication of low stability of starch molecules due to weak molecular arrangement, and this corroborates the theory that native starches are generally unable to withstand industrial temperatures. 
Peak height index (PHI) is an indication of the distribution of starch granules and its uniformity during gelatinization. Table 6 shows that there is reduction in the peak height of TS1 and TS2 in relation to TS0, this could be attributed to the effect of increasing the concentration of the crosslinking substrate. Peak height index (PHI) and $\Delta \mathrm{T}$ are observed to be negatively related; the wider the temperature range as a result of higher gelatinization temperature, the smaller the PHI as observed with TS1. This suggests that, the modified starches could be effective as a binding agent in solid dosage formulations.

\section{CONCLUSION}

In this study, we proved that, an agricultural waste constituting environmental nuisance, orange peels, could be employed as raw material for the green synthesis of starch obtained from Cyperus esculentus tubers. The modified TNS obtained had better water holding capacity, and thermal stability while retaining its microstructural properties, suggesting that, it may perform well as binding agents in the food and pharmaceutical industries.

\section{Acknowledgement}

The authors are grateful to the technical staff of the Department of Pharmaceutical Technology and Raw Materials Development, National Institute for Pharmaceutical Research and Development (NIPRD) for their support during the course of this stud

\section{Declaration of interest}

The authors declare no conflict of interest

\section{Tables for the manuscript:}

\section{Green preparation of citric acid cross-linked starch for improvement of physico-chemical} properties of Cyperus starch

\section{REFERENCES}

1. Adebayo AS, Itiola OA. Effects of breadfruit and cocoyam starch mucilage binders on disintegration and dissolution behaviors of paracetamol tablet formulations. J Pharm Tech. 2003;80:78-90.

2. Manek RV, Builders PF, Kolling WM, Emeje M, Kunle OO. Physicochemical and binder properties of starch obtained from Cyperus esculentus. AAPS Pharm Sci Tech. 2012;13: 379388.

3. Esezobo S, Ambujam V. An evaluation of starch obtained from plantain Musa paradisidca as a binder and disintegrant for compressed tablets. J Pharm Pharmacol. $1982 ; 34: 761-765$

4. Muazu J, Musa H, Bhatia PG. Evaluation of the glidant property of Fonio starch Res J App Sci Eng Tech. 2010;2:149-152.

5. Khunkitti W, Aromdee C, Vorarat S, Chitropas P. The potential of jackfruit starch for use as suspending agent and emulsifying agent. Songklanakarin J Sci Technol. 2006;8:145-155.

6. Onyishi IV, Chime SA, Kanu I. Application of Ipomea batatas starch as suspending agent in Acetaminophen suspension. Afr J Pharm Pharmacol. 2014;8:24-30.

7. Omojola M, Orishadipe AT, Afolayan M, Adebiyi AB. Preparation and physicochemical characterization of icacina starch citrate - a potential pharmaceutical/industrial starch. Agric Biol J N Am. 2012;3:11-16. 
8. Alcázar-Alay CS, Meireles MAA. Physicochemical properties, modifications and applications of starches from different botanical sources. Food Sci Tech (Campinas). 2015;35:215-236.

9. Isah S, Oshodi AA, Atasie VN. Physicochemical properties of cross linked acha (Digitaria exilis) starch with citric acid. Chem Int. 2017;3:150.

10. Tomasik P, Zaranyika MF. Nonconventional methods of modification of starch. Adv Carbohd Chem Biochem. 1995;51:243-318.

11. Rusli D, Azronnizan Q, Maaruf AG, Nik IND, Bohari MI. Hydroxypropylation and acetylation of sago starch. Malay J Chem. 2004;6:48-52.

12. Neelam K, Vijay S, Lalit S. Various techniques for the modification of starch and the applications of its derivatives. Int Res J Pharm. 2012;3:25-31.

13. Yadav BS, Guleria P, Yadav RB. Hydrothermal modification of Indian water chestnut starch: Influence of heat-moisture treatment and annealing on the physicochemical, gelatinization and pasting characteristics. LWT - Food Sci Tech (Campinas). 2013;53;211-217. 14. Abbas KA, Khalil SK, Hussin ASM. Modified starches and their usages in selected food products: A Review Study. J Agric Sci. 2010;2:90-100.

15. Maitra J, Shukla VK. Cross-linking in Hydrogels - A Review. Amer J Pol Sci. 2014;4:25-

31.

16. Shah N, Mewada RK, Mehta T. Crosslinking of starch and its effect on viscosity behavior. Rev Chem Eng. 2016;32:265-270.

17. Singh J, Kaur L, McCarthy OJ. Factors influencing the physicochemical, morphological, thermal and rheological properties of some chemically modified starches for food applications: A Review. Food Hydrocoll. 2007;21:1-22.

18. Hirsch JB, Kokini JK. Understanding the mechanism of cross-linking agents (POCL3, STMP, and EPI) through swelling behavior and pasting properties of cross-linked waxy maize starches. Cereal Chem. 2002;79:102-107.

19. Wattanachanta S, Muhammad K, Hashimb DM, Rahmanb RA. Effect of crosslinking reagents and hydroxypropylation levels on dual-modified sago starch properties. Food Chem. 2003;80:463-471.

20. Yin L, Zhu Z. Research on the preparation of crosslinked starch chlorinated with sodium hypochlorite. Wuhan University J Nat Sci. 2003;8:861-865.

21. Chowdary KPR, Chaithanya KK. Preparation and evaluation of cross linked starch urea. A new polymer for controlled release of Aceclofenac. Asian J Chem. 2010;22:4265-4270.

22. Omojola MO, Manu N, Thomas SA. Effect of cross linking on the physicochemical properties of cola starch. Afr J Food Sci. 2012;6:91-95.

23. Torrado M, Sandra C, Salgadoj M, Noelia R, Belinda P, Converti A, Domínguez J. Citric acid production from orange peel wastes by solid-state fermentation. Brazil J Microb.

2010;42:394-409.

24. Soccol CR, Vandenberghe LPS. Overview of applied solid state fermentation in Brazil Biochem Eng J. 2013;13:205-218.

25. Balasundram N, Sundram K, Samman S. Phenolic compounds in plants and agriindustrial by-products: Antioxidant activity, occurrence, and potential uses. Food Chem. 2006;99:191-203.

26. Rabetafika HN, Bchir B, Blecker C, Richel A. Fractionation of apple by-products as source of new ingredients: Current situation and perspectives. Trends Food Sci Technol. 2014;40:99-114. 
27. Dhandayuthapani K, Thiyageswaran G, Kumar R. Production of citric acid from banana waste by Aspergillus niger. Int J App Bioeng. 2008;2:1-3.

28. Vafina A, Proskurina V, Vorobiev V, Evtugin VG, Egkova G, Nikitina E.

Physicochemical and morphological characterization of potato starch modified by bacterial amylases for food industry applications. J Chem. 2018;8:1-9.

29. Rohr M, Kubicek CP, Kominek J. Citric acid. In- Biotechnology, Reed, G. and Rehm, H J. (Eds.), Verlag-Chemie, Weinheim; 1983:419-454.

30. Pandey A, Soccol CR. Bioconversion of biomass: A case study of lignocellulosics bioconversions in solid state fermentation. Brazilian Arch Biol Technol. 1998;41: 379-390.

31. Kunle OO, Ibrahim YE, Emeje MO, Shada S, Kunle Y. Extraction and physicochemical compaction properties of Tacca starch- a Potential Pharmaceutical excipient. Starch/Stärke. 2003;55:319-325.

32. Adebiyi AB, Omojola MO, Orishadipe AT, Afolayan MO, Olalekan D. Tacca starch citrate - A potential pharmaceutical excipient: Scholars Res Lib Arch App Sci Res. 2011;3:114121.

33. Kornblum SS, Stoopak SB. A new tablet disintegrating agent: Cross-linked polyvinylpyrrolidone. J Pharm Sci. 1973;62:43-49.

34. Yokoya F. Citric Acid Production. In: Industrial Fermentation Series, Campinas, SP, Brazil; 1992:1-82.

35. Mohammadi MS, Harnby N. Bulk density modelling as a means of typifying the microstructure and flow characteristics of cohesive powders. Powder Technol. 1997;92:1-8.

36. Kenneth A, Afolayan MO, Oberafo AA, Thomas S. Isolation and physicochemical characterization of Tigernut (Cyperus esculentus) starch as a potential industrial biomaterial. Int J Mat Sci App. 2014;3:37-41.

37. Coursey DG, Rasper V. Properties of starches of some West African yams. J Sci Food Agric. 1967;18:240-248.

38. Akpa JG, Dagde KK. Modification of cassava starch for industrial uses. Int J Eng Tech. 2012;2:913-919.

39. Emeje M, Kaita R, Isimi C, Buragohain A, Kunle O, Ofoefule S. Synthesis, physicochemical characterization and functional properties of an esterified starch. Afr. J. Food Agric Nutr Dev. 2012;65:369-374.

40. Isah S. Chemical modification of grains starch for improved functionality. Int J Chem Mat Sci. 2018;1:6-16.

41. Mariod AA. Gum arabic: structure, properties, application and economics, London, United Kingdom: Elsevier Ltd. Academic Press; 2018.

42. Jyothi AN, Moorthy SN, Sreekumar JN, Rajasekharan KN. Studies on the properties of citrate derivatives of cassava (Manihot esculenta Crantz) starch synthesized by microwave technique. J Sci Food Agric. 2007;87:871-879.

43. British Pharmacopoeia (BP).Vol. I and II: Her Majesty's stationary office, university, press, Cambridge, London; 2002.

44. Adane M, Endale A, Bultosa G, Abdel-Mohsen MG, Gebre-Mariam T. Isolation and physicochemical characterization of Godare (Colocasia esculenta) starch from Ethiopia. Ethiop Pharm J. 2006;24:13-22.

45. Emeje M, Isimi C, Kunle O. Effect of Grewia gum on the mechanical properties of paracetamol tablet formulations. Afr J Pharm Pharmacol. 2008;2:1-6. 
46. Ohwoavworhua FO, Adelakun TA. Some physical characteristics of microcrystalline cellulose obtained from raw cotton of Cochlospermum planchonii. Trop J Pharm Res. 2005;4:501-507.

47. Loss PJ, Hood LF, Graham HD. Isolation and characterization of starch from Breadfruit. Cereal Chem. 1981;58:282-286.

48. Omojola MO, Akinkunmi YO, Olufunsho KO, Egharevba HO, Martins EO. Isolation and physicochemical characterization of Cola starch. Afr J Food Agric Nutr Dev. 2010;10:28842900.

49. Xie X, Liu Q. Development and physicochemical characterization of new resistant citrate starch from different corn starches. Starch/Stärke. 2004;56:364-370.

50. Surendra AB, Parimalavilli R, Jaganadham K, Sudhakara JR. Chemical and structural properties of sweet potato starch treated with organic and inorganic acid. J Food Sci Tech 2014;1-9.

51. Park IM, Ibanez AM, Zhong F, Shoemaker CF. Gelatinization an Pasting Properties of Waxy and Non $\square$ waxy Rice Starches. Starch/Stärke. 2007;59:388-396.

52. McPherson AE, Jane J. Comparison of waxy potato with other root and tuber starches. Carbohyd Polym. 1999;40:57-70.

53. Bhupender SK, Rajneesh B, Baljeet SY. Physicochemical, functional, thermal and pasting properties of starches isolated from pearl millet cultivars. Int Food Res J. 2013;20:15551561.

Table 1. Organoleptic properties of Tigernut starch products (TS0, TS1, TS2 and TS3)

\begin{tabular}{lllll}
\hline Parameters & TSO & TS1 & TS2 & TS3 \\
\hline Color & White & off-white & off-white & off-white \\
\hline Odor & Odorless & characteristic & characteristic & Characteristic \\
\cline { 3 - 5 } & Tasteless & Bland & bland & Bland \\
\hline Texture & Simooth & Coarse & coarse & Coarse \\
\hline number of determinations $(n)=6$ & & &
\end{tabular}

Table 2. pHi of orange peel substrate

\begin{tabular}{ll}
\hline Day & pH \\
\hline 0 & $5.23 \pm 0.05$ \\
\hline 5 & $2.00 \pm 0.02$ \\
\hline
\end{tabular}




\begin{tabular}{ll}
10 & $2.79 \pm 0.01$ \\
\hline 15 & $2.30 \pm 0.02$ \\
\hline
\end{tabular}

number of determinations $(n)=3, \pm=$ standard deviation $(S D)$

Table 3. Flow properties of Tigernut starch products (TS0, TS1, TS2 and TS3)

\begin{tabular}{lllll}
\hline Parameters & TS0 & TS1 & \multicolumn{1}{c}{ TS2 } & TS3 \\
\cline { 1 - 4 } Angle of repose $\left(^{\circ}\right)$ & $33.06 \pm 1.79$ & $34.66 \pm 1.05$ & $30.39 \pm 1.01$ & $26.96 \pm 1.02$ \\
\hline Bulk density $(\mathrm{g} / \mathrm{mL})$ & $0.46 \pm$ & $0.49 \pm$ & $0.48 \pm$ & $0.50 \pm$ \\
& 0.01 & 0.01 & 0.01 & 0.01 \\
\hline Tapped density $(\mathrm{g} / \mathrm{mL})$ & $0.68 \pm$ & $0.71 \pm$ & $0.68 \pm$ & $0.67 \pm$ \\
& 0.01 & 0.02 & 0.01 & 0.01 \\
\hline Hausner ratio & $1.47 \pm$ & $1.45 \pm$ & $1.42 \pm$ & $1.34 \pm$ \\
& 0.02 & 0.01 & 0.04 & 0.03 \\
\hline Carr's index $(\%)$ & $32.18 \pm 1.03$ & $30.36 \pm 1.57$ & $29.24 \pm 2.06$ & $25.24 \pm$ \\
& & & & 1.30 \\
\hline
\end{tabular}

number of determinations $(n)=3, \pm=$ standard deviation $(S D)$

Table 4. Physicochemical properties of Tigernut starch products (TS0, TS1, TS2 and TS3)

\begin{tabular}{lllll}
\hline Parameters & TSO & TS1 & TS2 & TS3 \\
\cline { 2 - 5 } $\mathrm{pH}$ & $5.25 \pm$ & $4.07 \pm$ & $3.39 \pm$ & $3.87 \pm$ \\
& 0.02 & 0.02 & 0.06 & 0.02 \\
\hline Water holding & $85.55 \pm$ & $91.37 \pm$ & $90.67 \pm$ & $96.69 \pm$ \\
capacity (\%) & 1.05 & 5.42 & 3.40 & 1.88 \\
\hline Foam capacity (\%) & $3.07 \pm$ & $3.33 \pm$ & $3.33 \pm$ & $3.33 \pm$ \\
& 1.01 & 1.15 & 1.15 & 1.15 \\
\hline Emulsion capacity (\%) & $15.33 \pm$ & $15.33 \pm$ & $15.33 \pm$ & $15.33 \pm$ \\
& 0.58 & 0.58 & 0.58 & 0.58 \\
\hline Moisture content (\%) & $8.00 \pm$ & $7.80 \pm$ & $8.10 \pm$ & $9.20 \pm$ \\
& 0.30 & 0.10 & 0.10 & 1.00 \\
\hline Moisture sorption & 5.87 & 5.42 & 5.84 & 5.54 \\
capacity (\%) & & & \\
number of determinations(n) $=3, \pm=$ standard deviation $(S D)$ &
\end{tabular}


Table 5. Swelling power Tigernut starch products (TS0, TS1, TS2 and TS3)

\begin{tabular}{lllll}
\hline Temperature $\left({ }^{\circ} \mathbf{C}\right)$ & TS0 & TS1 & TS2 & TS3 \\
\hline 30 & $2.33 \pm 0.43$ & $2.38 \pm 0.11$ & $2.09 \pm 0.07$ & $2.55 \pm 0.03$ \\
\hline 40 & $2.52 \pm 0.11$ & $2.79 \pm 0.09$ & $2.64 \pm 0.17$ & $2.70 \pm 0.43$ \\
\hline 50 & $2.44 \pm 0.19$ & $2.43 \pm 0.17$ & $2.22 \pm 0.04$ & $2.63 \pm 0.09$ \\
\hline 60 & $2.68 \pm 0.13$ & $2.69 \pm 0.05$ & $2.54 \pm 0.17$ & $2.97 \pm 0.17$ \\
\hline 70 & $5.59 \pm 0.40$ & $5.53 \pm 0.14$ & $3.56 \pm 0.10$ & $5.22 \pm 0.42$ \\
\hline 80 & $8.77 \pm 0.93$ & $8.03 \pm 0.08$ & $8.00 \pm 0.30$ & $8.03 \pm 0.11$ \\
\hline 90 & $7.44 \pm 0.34$ & $9.18 \pm 0.76$ & $7.35 \pm 0.24$ & $8.01 \pm 0.17$ \\
\hline
\end{tabular}

number of determinations $(n)=3, \pm=$ standard deviation $(S D)$

Table 6. DSC parameters of the native and modified starches

\begin{tabular}{|c|c|c|c|c|}
\hline Parameter & TS0 & TS1 & TS2 & TS3 \\
\hline Onset temperature $\left({ }^{\circ} \mathrm{C}\right)$ & 60.35 & $\overline{59.84}$ & 104.16 & 113.18 \\
\hline Peak temperature $\left({ }^{\circ} \mathrm{C}\right)$ & 125.59 & 141.60 & 124.47 & 132.88 \\
\hline Conclusion temperature $\left({ }^{\circ} \mathrm{C}\right)$ & 134.44 & 293.41 & 129.52 & 132.92 \\
\hline Enthalpy of gelatinization $[\mathrm{J} /(\mathrm{g} * \mathrm{~K})]$ & 1926.95 & 2120.73 & 488.44 & 1096.20 \\
\hline$\Delta \mathrm{T}\left({ }^{\circ} \mathrm{C}\right)$ & 74.09 & 233.57 & 25.36 & 25.74 \\
\hline Peak Height Index (PHI & 26.01 & 9.07 & 19.26 & 42.59 \\
\hline
\end{tabular}




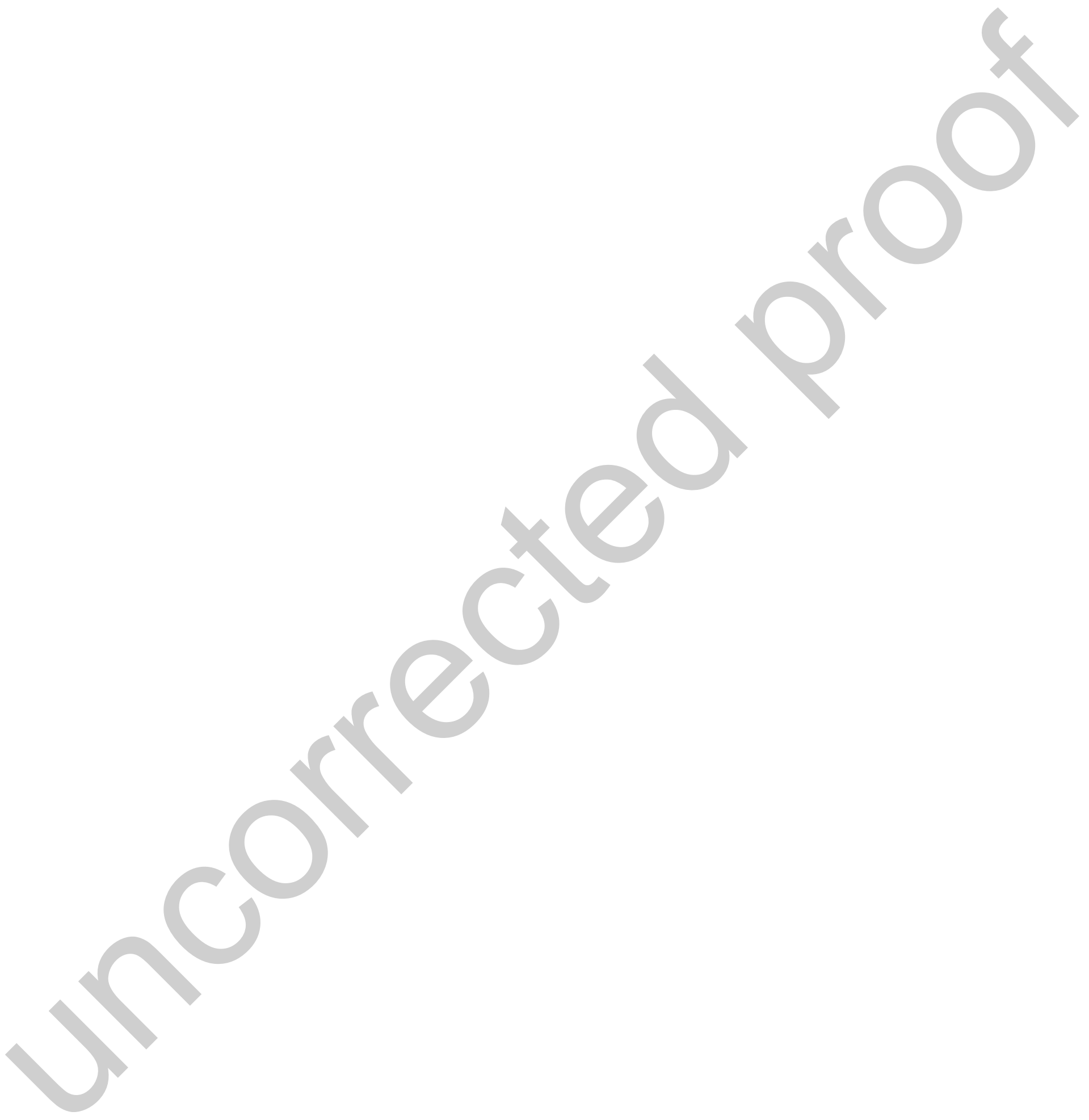

